\title{
THE EXTERNAL POLICY OF THE EUROPEAN ECONOMIC COMMUNITY
}

\author{
J. F. DENIAU*
}

In a world where things, and in particular things economic, are becoming more and more interlocked, it is not always easy to make a neat distinction between the domestic policy of a country or group of countries and its policy for dealing with external affairs. This is what the six countries of the Common Market have been finding since the inauguration of the European Economic Community (E.E.C.).

They have been finding it, first of all, in a very practical way in the implementation of the internal machinery of the Treaty of Rome-that is to say, with the elimination of customs duties and quantitative restrictions between the Member States. This has led much more quickly than expected to technical problems that involve coordination of their relations with nonmember countries, especially with those practicing state trading or those where abnormal conditions of competition obtain. It may, indeed, be difficult to establish the free circulation of certain goods within the Common Market so long as the aims of each Member State's bilateral agreements with nonmember countries-that is to say, their import policies-remain widely different. This being so, unification of the policies adopted by Member States towards nonmember countries must advance strictly in step with unification of the internal market.

When the six countries were negotiating the Common Market, they no doubt felt that the most difficult problems, or at least the most immediate ones, would be those relating to trade among the six countries themselves. This may explain the fact that the Treaty of Rome does not contain a special chapter on the Community's external relations. Apart from the provisions on the establishment of the common external tariff itself 1 -that is to say, the application of one of the constituent elements of the customs union of the Six-the expressions used are in most cases of a fairly general nature:

I. declarations of intention, stating the liberal intentions of the Community $;^{2}$ and

2. procedures under which to participate in future negotiations, to elaborate, step by step, a common commercial policy, ${ }^{3}$ to pursue this common policy after the end

* Licence en droit et Diplôme de doctorat d'Etudes Supérieures de Droit 1949, (Economic Politique), Diplôme de l'Institut d'Etudes Politiques 1949, Licence es Lettres, Ethnologic et Sociologie 1947, University of Paris. Ecole Nationale d'Administration. Inspecteur des Finances; Directeur, The Association with the Third Countries, Commission of European Economic Community, Brussels, Belgium. Author, LE Marche CoManuN (1958; rev. ed. x96x).

${ }^{1}$ E.E.C. Treaty arts. 18-29.

${ }^{2}$ E.g., id. art. xIo.

s Id. art. III. 
of the transition period; ${ }^{4}$ and finally, to enable nonmember countries either to join the Community ${ }^{5}$ or to associate themselves with it. ${ }^{6}$

Experience has shown that the internal machinery of the Common Market has so far functioned well and has even made possible a considerable speed-up in the implementation of the Treaty, but it has also shown that what may be very pressing and very difficult questions have arisen in the Community's relations with nonmember countries. These questions have a direct bearing on the life and character of the Common Market as a whole; and ever since the entry into force of the Treaty of Rome-that is to say, since January $195^{8}-$ much of what has been done by the Community, and especially by the officials of the E.E.C., has revolved around the issues they pose.

The first need was to coordinate the activities of the six Governments and to find a common position on a certain number of problems that had existed before the establishment of the Common Market, but that could be reviewed in the light of the new situation. The second was to have the E.E.C. recognized for what it was and to define in broad outline the relations it could have with its partners. There are, therefore, always two parts to the definition of the Common Market's attitude: first, the consultation and coordination procedure between the various organs of the Community-especially the Commission and the Council of Ministers; and second, liaison work and the elaboration of a common position with regard to nonmember countries. The emergence of the Common Market on the international plane has been observed in many ways. The Community has taken part as such in the work of many international organizations, such as General Agreement on Tariffs and Trade (G.A.T.T.) and Organization for European Economic Cooperation (O.E.E.C.). With some of them-O.E.E.C., the International Labor Office (I.L.O.), the Council of Europe, and certain specialized agencies of the United Nations-it has concluded agreements for practical cooperation covering such items as the attendance of observers at meetings and the exchange of information. Moreover, a number of nonmember countries (seventeen at present) have accredited diplomatic missions to the Community in Brussels; they include the United States, most European countries, and other countries as different in character as Japan, Australia, and Brazil. In this way, recognition of the international role that the Community could and should play has found a first practical expression.

\section{I}

To begin with, the Community faces a series of major problems that would have confronted the Governments of the Member States even if they had not set up a Common Market among themselves. These are mainly such problems as the coordination of cyclical policies, the development of certain countries in order to ensure a better equilibrium in their trade with the industrialized countries, the stabilization

\footnotetext{
"Id. art. Ir4.

Id. art. 237.

'Id. art. 238.
} 
of the basic commodity markets, the situation of agriculture in the industrialized countries, and the problems of commercial relations with low-wage countries or countries practicing state trading. All these problems face the western countries as a whole and call for a greater measure of international cooperation. Far from making them more difficult, the establishment of the E.E.C. is intended to facilitate their solution. It is easier to reach international understanding if six of the parties concerned have already agreed among themselves, and it is also very much easier to make an effort on the required scale if the resources of some of the partners have already been pooled and their positions coordinated. Moreover, the existence of an independent body, such as the E.E.C. provides, able to objectively appraise the questions for discussion and settlement, must serve to facilitate agreement on any solution proposed. The Common Market, therefore, introduces a twofold new element: politically, the revival of international cooperation inherent in the Common Market's own unification; and, from a more strictly economic point of view, its own weight and the responsibilities that this entails.

The second set of problems derives from the establishment of the Common Market itself and from the reactions of the nonmember countries faced with this considerable change in international economic conditions. If these reactions and the weight of the Common Market and its responsibilities are to be fully understood, it may be useful to recall certain figures concerning the part played by the E.E.C. in world trade.

A large part of the trade done by the countries of the Common Market is with other members of the Community: it varies from twenty-five to more than forty per cent, for both imports and exports. The average amounts to about one-third. Trade with European nonmember countries accounts for about another third. The final third is covered by relations with the non-European countries, especially the United States. Taken as a whole, the E.E.C.'s share in world trade, as is shown in table one, often places it above the United States and on an approximately equal footing with as vast an association as the Commonwealth.

\begin{tabular}{|c|c|c|}
\hline \multicolumn{3}{|c|}{$\begin{array}{c}\text { TABLE I } \\
\text { WORLD TRADE } \\
\text { (r959 FIGURES IN } \oint_{\text {I,000 MILLION) }}\end{array}$} \\
\hline & Imports & Exports \\
\hline World trade & $104 \cdot 4$ & 99.9 \\
\hline United States & $\mathrm{x} 5.0$ & $17 \cdot 4$ \\
\hline E.E.C. & $24 \cdot x$ & 25.2 \\
\hline Sterling Area (including United Kingdom) & 24.8 & $2 x \cdot 5^{\mathrm{a}}$ \\
\hline United Kingdom & II.2 & $9 \cdot 3$ \\
\hline
\end{tabular}

As importer of foodstuffs and raw materials, the Community accounts for about thirty-one per cent of world trade, the United States for sixteen per cent, and the United Kingdom for eighteen per cent. In other words, the Community offers 
an outlet for these products that is almost double that of the United States and greater by two-thirds than that of the United Kingdom.

As an exporter of industrial goods, it covers some thirty-three per cent of world: trade, whereas the United States accounts for twenty-six per cent and the United. Kingdom for sixteen per cent. In other words, its sales are double those of the: United Kingdom and almost thirty per cent higher than those of even the United. States.

If, finally, we exclude trade between the Community countries, the United: States, and the United Kingdom, in order to find out the significance of thesethree great trading partners for the rest of the world, we see that industrial exports from the United States to the rest of the world are still ahead of those of the Community, which, in turn, exceed British sales by forty per cent; however, as. a purchaser of primary products from these regions, the Community already outstrips by one-third both the United States and the United Kingdom.

From these figures, one can draw certain conclusions that will illustrate the attitude of the Community towards nonmember countries:

r. The Community is the world's greatest importer of raw materials. This is of direct interest to the countries in course of development and, therefore, to a spherein which the Community has a particular responsibility and where it can exercise a positive influence, if only by the volume of its trade.

2. The Community can in no way be regarded as a closed, inward-looking entity. It is, in fact, in large measure open to the world and for the greatest part of itsactivities depends on its relations with the rest of the world.

3. Its relations with the rest of the world are spread almost equally over the various: geographical areas. It is, therefore, very difficult to grant privileges to onesector rather than to another. In particular, the problem of the relations of the Common Market with its European neighbors should not be considered in isolation, but must on the contrary be seen in the wider setting of the over-all. western or even world policy of the Common Market.

\section{II}

At the same time, it is this very importance of the Community that has given rise to anxiety in certain countries. Quite apart from any political consideration and! looked at merely from the point of view of trade, the establishment in Europe of a customs union, with all the advantages this entails for the participating countries and with the change it could bring about in the habits of the nonmember countries, was. bound to arouse certain reactions. The customs union of the Common Market is, it is true, in conformity with the rules of G.A.T.T. and the level of its external tariff, calculated on the principle of the arithmetical mean of the tariffs of the Member States, is also in conformity with G.A.T.T. Its level is comparable with, or even. lower than, that of other major industrial countries. Moreover, though the customs duties of certain of the Member States must be raised to the level of the common 
external tariff, others must be very considerably lowered, and it might even be considered that the reductions will be much more important than the increases, since they will more especially affect two of the countries of the Community with the largest populations-namely Italy and France (the German tariff is already very close to the future common external tariff). For the products contained in List $G$-that is to say, those that had been excluded from the general rules of calculation and for which the tariff was fixed in special negotiations after the entry into force of the Treaty of Rome-the average of all the rates agreed is also below the average of the previous tariffs, and is, therefore, in conformity wth the G.A.T.T. rules. But in this matter, it is not the legal aspect that constitutes the main problem.

Anxiety was first expressed within G.A.T.T. itself, and in particular by nonEuropean countries in the process of development.. It should be remembered that the Treaty of Rome includes the association with the Common Market of a number of countries, mainly in Africa, and provides that there shall be both commercial arrangements and financial aid to help these countries. This association, and in fact, the Treaty itself, seemed to other countries to constitute a danger to their own exports or their own development. Replying to these fears, the Community has restated its confidence in the beneficial effects of the Common Market on all nonmember countries as a result of the internal expansion that is expected to result from the machinery of the Treaty of Rome. It is the basic philosophy of the Common Market that leads the Community to adopt this position. Previous experience, such as that gained with Benelux, has, moreover, shown that the development of trade among countries forming a customs union has had no ill effect on trade with outside countries. On the contrary, the growth of investments and consumption within the customs union, in fact, brings with it an expansion of imports from nonmember countries. One can point, for instance, to the fact that, on the basis of the provisional figures for Ig6o, the Common Market's internal trade has increased by twenty-five per cent over the previous year and its external trade by more than eighteen per cent, imports gaining considerably more than exports. In this light, it may be considered that the internal expansion of the Six is one of the best guarantees of the beneficial effects that the Treaty will have for the countries outside the Common Market. Table II shows this increase of trade with nonmember countries, both on a European and a world scale. The Community has, moreover, repeated its readiness to discuss with its partners any practical difficulty that might arise and to seek ways of dealing with it. But discussion is difficult, since it turns on hypothetical cases and largely concerns a gamble on the future consequences of the Treaty, since so far no concrete difficulty has arisen.

This, however, does not, of course, relieve the Community of the duty to make special effort in its relations with the countries in the process of development. As has been stressed before, the Community has a definite responsibility in this respect. Without prejudice to the machinery laid down in the Treaty for the benefit of the directly associated countries, this regional assistance must be supplemented by par- 
TABLE II

Development of the IMPORTS OF the E.E.C.

(Intra-community trade excluded)

\begin{tabular}{|c|c|c|c|c|}
\hline $\begin{array}{l}\text { Imports to the com- } \\
\text { munity and their source }\end{array}$ & $\begin{array}{c}1958 \\
\text { millions }\end{array}$ & $\begin{array}{c}1959 \\
\text { millions }\end{array}$ & $\begin{array}{c}1960 \\
\text { millions }\end{array}$ & $\begin{array}{l}\text { Per cent increase } \\
\text { from } 1958 \text { to } \\
1960\end{array}$ \\
\hline 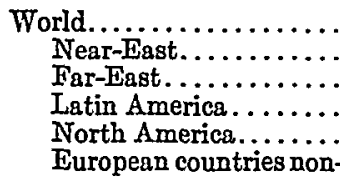 & $\begin{array}{r}\$ 14,610 \\
1,904 \\
912 \\
1,561 \\
3,238\end{array}$ & $\begin{array}{r}\$ 15,411 \\
1,893 \\
899 \\
1,630 \\
2,981\end{array}$ & $\begin{array}{r}\$ 17,753 \\
1,980 \\
1,139 \\
1,812 \\
4,276\end{array}$ & $\begin{array}{l}+21.5 \\
+3.9 \\
+24.8 \\
+16.0 \\
+24.2\end{array}$ \\
\hline member of the I.E. C.. & 4,263 & 4,623 & 5,368 & +25.9 \\
\hline
\end{tabular}

ticipation in other forms of aid that will be open to all countries in the course of development. Under this heading, the Community as such is already sharing in the work of the Development Assistance Group, the first meeting of which took place in Washington in I960. This is, moreover, one of the fields in which coordination of the positions adopted by the Community and the leading industrial countries, especially the United Kingdom and the United States, is particularly desirable.

There are also some European countries, whose attitude towards the unification of the Six and the changes that this can bring about, has been very reserved. The report of the Spaak Committee, which was to serve as the basis for the Treaty of Rome, was adopted by the six countries at the Conference of Venice in May 1956 . In July 1956, the Council of Ministers of the O.E.E.C., acting on the initiative of Great Britain, undertook to study a draft for a free trade area, which reflected the desire to set up as soon as possible a means of extending the commercial advantages of the Common Market to all its neighbors and of eliminating from the very outset any possibility of differential treatment. These negotiations were suspended at the end of 1958 without a satisfactory conclusion having been reached. It may be appropriate at this point to recall the reasons for this state of affairs, which are to be found both in the main lines of the agreement proposed and in a deep-rooted misunderstanding of the true nature of the Common Market.

First, the technical difficulties. It is clearly more difficult to reach agreement among seventeen countries than among only six, especially if the agreement in question would have very considerable importance and would provide for the eventual complete elimination of all customs duties and quota restrictions among the member states. Moreover, while the six countries of the Common Market are very similar in their structure and are already closely linked by trade, if only because they have common borders, the proposed free trade area embraced countries differing widely from one another in their economic development and in their trade patterns. Some of them do a very important part of their trade with the Common Market, whereas others at present have very much bigger outlets outside Europe 
than in the Common Market, so that the specifically European commitments that they can undertake are correspondingly limited. On the political plane also, their situation is different: for while the six countries of the Common Market belong to the same alliances, some of the countries that took part in the negotiations for the free trade area maintain a position of strict neutrality.

Furthermore the very system proposed-that is to say, a free trade area in which each member would be free to maintain its own customs tariffs vis-à-vis nonmember states at the level, high or low, that suited its convenience, and to preserve its own autonomy in commercial policy-gave rise to a number of practical difficulties. It is true that this system took into account the very great diversity of economic goals and political wishes of the countries promoting the free trade area. But against this advantage, it had the drawback of creating a number of technical and administrative problems (e.g., the diversion of trade, the determination of origin, the calculation of added value, and, possibly, the imposition of compensatory charges) that added to the other difficulties of the negotiations and made them even more complex.

While in the Common Market the six countries considered that the attainment rof the commercial aims, and in particular the total elimination of customs duties, must be backed by a series of undertakings and by a certain common discipline in other fields, which, in fact, affect the development of trade, the basic attitude of the other European countries was rather the reverse of this. To them, for either the political or the economic reasons already mentioned, the free-trade-area agreement would have had to be strictly limited to certain commercial benefits, with undertakings in other fields kept to a minimum. Quite apart from any ideological conflict, this undeniably involved technical dangers for the Common Market and its development. There was, in fact, the risk that difficulties might arise among the Six in the implementation of the Treaty, from motives that would have had nothing to do with the Community itself, but that would have been due to imperfections or tc the lack of adequate undertakings on the part of the other members of the free trade area. It has been pointed out that the first years of the implementation of the Treaty have shown how unification vis-à-vis the outside world was essential to ensure internal unification. In these circumstances, to extend to a large number of widely different nonmember countries much of the internal machinery of the Treaty, but in the context of very different undertakings, and in particular without any commitment on commercial policy and on relations with the outside world in general, could have been tantamount to preventing the Common Market from reaching its goal. The force of this argument can be seen from the institutional point of view, when it is remembered that the Common Market has, as it were, to be the motive force for political unification in Europe; but it can also be appreciated from the strictly economic point of view.

The main benefits to be hoped for from the Common Market, in fact, do not lie in the first reductions of duties or increases of quotas. Their effect, though certainly 
favorable, is limited. The main benefits-the growth of investment, the increase of consumption, and structural reorganization-are to be expected from the conclusion of the measures agreed on-that is to say, from the complete establishment of a single market and the fusion of existing national economies. If this is borne in mind, it is clear that one must avoid anything that might seriously prejudice the chances of completely implementing the Treaty or that might change it into an agreement creating a mere preferential area, in conformity neither with its vital economic and political aims nor even with the rules of G.A.T.T.

This, in fact, is where it may be said that the negotiations for the free trade area involved not only technical difficulties, but a deep-rooted misunderstanding of the true nature of the Common Market. Some countries, in fact, wished to look upon the latter as no more than a mere commercial arrangement that could easily, with a little goodwill, be replaced by another and wider commercial arrangement of a different character. For the Six, however, the purely commercial aspects of the Treaty of Rome are indissolubly linked, as has been said before, with a series of broader economic commitments that would lead to the degree of unity they are seeking to attain. They believe that over and above the free movement of goods, they must ensure freedom of movement for persons, capital, and services; that a number of fundamental conditions of competition must be established or brought into line, especially in the social field and also by the elaboration of a common agricultural policy; and, finally, that in external relations, the establishment of a common customs tariff is one of the elements indispensable to the completely free movement of goods within the Community.

Furthermore, the magnitude of these economic commitments in itself gives a clearly political character to the whole operation. In the first place, it is necessary, if these economic commitments are to be fulfilled, to take extremely important decisions in the whole field covered by the Treaty and to arrive at very difficult compromises on issues vital to the Member States. This is not possible unless there is a constant political will. Secondly, the economic unity thus reached must make possible further progress in political integration.

This is, moreover, in accordance with the spirit of G.A.T.T., which permits deviations from the most-favored-nation clause, but subject to an assurance that what is being done will really lead to unification, to the establishment of a new economic unit among the countries concerned. In such cases, differential treatment becomes no more than a transitory tariff measure, justified by the end in view. To the extent, however, that such an operation would be likely to bring about no more than partial trade advantages and thus to set up a new preferential area, it would amount to a totally unjustified disruption of international trade. This criterion provides the touchstone for any wider solution in Europe. To the extent that such an association represents a serious step towards unification, that it offers a chance of ultimate success, that it constitutes a major srengthening of both economic and political cohesion in Europe, a differential treatment covering all the European 
countries could be justified. On this latter point, however, and especially with regard to the United States, the recent trend in economic relations between Europe and North America calls for additional caution.

\section{III}

Economic relations between Europe and the United States are very different from what they were twelve years ago when the O.E.E.C. was set up. At that time, the economic and monetary situation of Europe was extremely serious owing to the ravages caused by the war. It is to the honor of the United States that it recognized the dangers of this situation and sought to remedy them. To serve this purpose, the O.E.E.C. was given a twofold task: to ensure the allocation of Marshall aid credits; and to promote in Europe a liberalization of trade and a greater degree of cooperation, by which European recovery could be speeded. In view of the situation in Europe and especially the marked imbalance in its trade with the United States, which was reflected in a disastrous shortage of dollars, it was accepted that this liberalization of trade might be operated for the benefit of the European countries alone and, therefore, with a certain degree of discrimination against the United States.

Today the situation, although not reversed, is very different. Europe is selling more and more to the United States, and there is increasing stability in trade balances. Most of the European currencies have regained some degree of strength, and since the beginning of I959, almost all of them have again become largely convertible. One of the first consequences of this has been the transformation of the European Payments Union into something more flexible. Another consequence is that Europe as a whole can no longer be regarded as a partner requiring the assistance of the United States and entitled to privileged treatment in relation to the United States. On the contrary, in view of the American situation, it is necessary to avoid all discrimination-that is to say, all differential treatment. It is important to promote a liberal policy in European-American relations, based on equality, which will be to the advantage of both sides and will avoid any action which might provoke a return to protectionism.

The E.E.C. has been fully conscious of this fact. It seemed that neither economically (the American balance-of-payments situation), nor legally (because the return to European convertibility makes quota discrimination against the dollar no longer acceptable), nor politically, was there any justification for Europe as a whole to envisage a system based on differential treatment of the United States. Such a system could only be considered if, through its various mechanisms, economic as well as institutional, it offered a guarantee of a positive and really constructive contribution on both the European and world level.

This anxiety not to establish in Europe a commercial system that would amount to unjustified discrimination against others, especially the United States, is certainly well-founded as regards present relations between the United States and Europe; 
but the same applies equally to other nonmember countries. The developing countries in particular would be hard pressed to understand why the richest countries should establish amongst themselves a preferential area for the sole benefit of their own commercial interests and should do this at a moment when it was essential that the efforts of the leading countries should be coordinated in order to improve international trade.

\section{IV}

Nevertheless, this does not mean to say that the Common Market has done nothing with regard to its European partners. On the contrary, it has worked out a policy and has already adopted a number of important measures to implement it. After the suspension of the negotiations on the free trade area in the "Maudling Committee" at the end of 1958 , the Commission of the Common Market drew up a memorandum in which the following principles and lines of action were set out:

I. The Community remains open. Any European country can associate itself with it or even join it, and in this way participate in all the commercial advantages of the Common Market. But it must be realized that such participation in the advantages implies the acceptance of a certain form of discipline or commitments that will ensure both the smooth functioning of economic integration in Europe and the conformity of the operation with the general principles referred to earlier.

2. Over and above this serious and constructive possibility of association, which remains desirable, the Common Market can at once adopt a liberal policy vis-à-vis its European partners that will mitigate any anxieties or difficulties they may experience and that will take account of their specific problems.

3. Such a liberal policy vis-à-vis its European neighbors must not be divorced from the Common Market's attitude to other countries or groups of countries. On the contrary, the Community should make a positive contribution as part of a world-wide liberal policy without any discrimination.

Such a liberal policy has already shown fruit in a certain number of concrete measures adopted. In the case of quantitative restrictions, the Community decided, when the first quota enlargements were made within the Community on the way to the full Common Market, to allow the other European countries to share in the benefits derived from the major part of these enlargements. The same was done at the time of the second enlargement, made in accordance with the provisions of the Treaty of Rome. In order, however, to take account of the changes in the situation between Europe and the rest of the world and in particular the United States, discrimination for the benefit of one geographical area and against another was no longer considered justifiable. Under these conditions, the enlargements were made in a way that would benefit all the contracting parties of G.A.T.T. to whom the most-favored-nation clause applies. More recently, in May I960, it was decided, in connection with the speedier implementation of the Treaty, that all industrial quotas amongst the Member States should be completely abolished at an early date. Here, 
again, the benefit of the operation would be extended to nonmember countries. It can, therefore, already be said that the problem of differential treatment in the field of industrial quotas virtually no longer exists, although at the end of 1958 , it was considered by the European partners of the Common Market to be the most difficult of the problems and gave rise at that time to fairly serious objections of principle, especially when at the time of the first quota enlargement already mentioned, the Community decided not to extend to other European countries the three per cent enlargement of oil quotas.

There remains, therefore, only the tariff problem; but this is a question not of principle, but of degree. It is true that a very high tariff can be prohibitive or can bring with it diversions of trade, especially in the traditional pattern of trade. On the other hand, a sufficiently low tariff is perfectly compatible with the normal development of international trade. The E.E.C. has acted along those lines.

When the first internal tariff reduction of ten per cent was carried out within the Community, on the way to the full Common Market, a certain extension for the benefit of nonmember countries was granted; once again, it covered all the contracting parties of G.A.T.T. to whom the most-favored-nation clause applies. The same procedure was envisaged at the time of the second tariff reduction amongst the Six, subject to the Community's trading partners and especially its European neighbors being prepared to grant a certain degree of reciprocity. More important, however, was the decision, taken in connection with the speedier implementation of the Treaty, that the first approximation towards the common external tariff, to be carried out on January I, I96I, should be carried through on the basis of that tariff reduced by twenty per cent. This reduction was practical proof of the Community's will to follow the most liberal tariff policy vis-à-vis the outside world. The twenty per cent reduction may be made permanent, provided that nonmember countries, especially the European countries, agree to grant a certain measure of reciprocity. In thus making concessions on its tariff-which are to be taken into account in later negotiations but to be applied forthwith-the Community wished not only to mitigate any difficulties that nonmember countries might experience, but also to commit the world's leading industrial countries to new tariff negotiations that could bring about a considerable improvement of trading conditions throughout the world.

In the same spirit, the E.E.C. was the first to take up the proposals made by the American Government (Dillon proposals) for a series of tariff negotiations in G.A.T.T. Indeed, it was largely with these negotiations in mind that the Community made the advance gesture of the twenty per cent reduction on the common tariff. The Community has not excluded the possibility of other similar reductions being made later.

$\mathrm{V}$

The establishment of the "Seven" of the European Free Trade Association (E.F.T.A.) in November 1959 introduced a new element into the situation, but 
without fundamentally altering the facts. The Association is made up of seven countries (Great Britain, Sweden, Switzerland, Denmark, Norway, Austria, and Portugal) that do not belong to the Common Market. It does not include five European members of the old O.E.E.C.--namely, Ireland, Iceland, Greece, Turkey, and Spain.

In as much as this association of the Seven is based on principles and machinery that are very close to the original British plan for a free trade area, and, therefore, very different from those of the Common Market, it does not facilitate the search for a comprehensive solution. This is, however, true from the technical point of view, and has nothing to do with any purely tactical considerations. It might also be said to lend further emphasis to the need for a liberal policy in Europe, reflected in reciprocal tariff concessions. Only if and when actual difficulties were created for trade by unduly high customs tariffs would it be possible to speak of an "economic division of Europe," which might even lead to some political tension. This situation has not arisen and is not likely to arise. In fact, the problem of differential quota treatment has already ceased to exist-as has been pointed out. If the two groups agree to some reduction of their tariffs either in G.A.T.T. or other negotiations, the risk of any damage to the established pattern of trade will become extremely slight. The action taken so far by the Community reflects this aim.

After the decision of January 1960, a committee was set up for discussions and negotiations between the Common Market and its European partners, especially those belonging to the E.F.T.A. This committee, which is known as the "Committee of Twenty-one" (since apart from the other European countries, the United States and Canada are full members), has done a great deal of work in the course of this year. On a number of occasions, the Community has made the following proposals:

I. A reduction of the common tariff, in the light of certain reciprocal concessions from the members of the E.F.T.A.; and

2. further studies to cover any particular difficulties that might arise in the discussions concerning specific solutions in conformity with the rules of G.A.T.T. This is, as it were, a double approach: first, a liberal policy that a priori reduces the scope of any possible difficulties by reducing the level of tariff barriers; and then additional action, case by case, wherever it is required because of continuing specific difficulties.

Some remarks must be made about these proposals. While their effect is European, they also have world-wide repercussions because of the play of the most-favored-nation clause. Further measures of this kind have a long-term incidence that is not to be neglected, although they have sometimes been described as purely short-term or partial solutions. They commit the Community to a liberal approach, and this can have a considerable influence on its internal structure as well as on its future development; they also commit, or endeavor to commit, 
the leading industrial countries in the same way. As for the specific difficulties, it must be pointed out once again that so far none of them has arisen, and that on the contrary the Common Market is an area that is importing more and more; and the more firmly the liberal policy can be applied, the smaller will be the risk of specific difficulties arising in the future. Table III gives details, for the members of the E.F.T.A., of the development of trade with the E.E.C., and shows their increased trade with the Community as a result of the latter's economic expansion.

TABLE III

Development of the Imports of the E.E.C.

(Intra-community trade excluded)

\begin{tabular}{|c|c|c|c|c|}
\hline $\begin{array}{l}\text { Imports to the com- } \\
\text { munity and their source }\end{array}$ & $\begin{array}{c}1958 \\
\text { millions }\end{array}$ & $\begin{array}{c}1959 \\
\text { millions }\end{array}$ & $\begin{array}{l}1960 \\
\text { millions }\end{array}$ & $\begin{array}{l}\text { Per cent increase } \\
\text { from } 1958 \text { to } \\
1960\end{array}$ \\
\hline 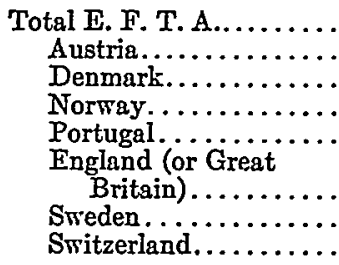 & $\begin{array}{r}\$ 3,571 \\
440 \\
391 \\
207 \\
76 \\
\\
1,160 \\
692 \\
605\end{array}$ & $\begin{array}{r}83,906 \\
452 \\
422 \\
211 \\
72 \\
\\
1,363 \\
730 \\
656\end{array}$ & $\begin{array}{r}\$ 4,6 C 0 \\
535 \\
419 \\
237 \\
83 \\
\\
1,534 \\
381 \\
771\end{array}$ & $\begin{array}{l}+24.8 \\
+21.5 \\
+7.1 \\
+14.4 \\
+9.2 \\
+32.2 \\
+27.3 \\
+27.4\end{array}$ \\
\hline
\end{tabular}

It is, of course, true that the way trade will develop cannot be judged simply from the statistics of the day; and it is perfectly understandable that some countries, especially those who do a large part of their trade in the Common Market, should feel some concern about more long-term economic developments and should wish for an immediate share in the internal advantages of the Treaty. The trade aspect is not the only one; the question of investments may also be of importance. To such countries, anxious to obtain definite or over-all commitments and guarantees, the possibility of association with or membership of the Community remains open.

The distinction between these two possibilities, based on two separate articles of the Treaty, must be clearly understood. Membership ${ }^{7}$ would normally mean the acceptance of all the principles and the entire machinery of the Treaty of Rome. It would mean that the Community would increase its members, the new Member States subscribing fully to its objectives, both economically and politically. Associa$\operatorname{tion}^{8}$ is a more flexible formula. It creates no new member of the Common Market, but establishes between a given country and the unit formed by the Six a series of undertakings and mutual bonds, while each partner retains a certain measure of autonomy. The flexibility of association as a solution of the problem can show itself in two ways. On the one hand, particular account can be taken in practice of the specific problems of the countries seeking association. On the other hand,

${ }^{7}$ E.E.C. Treaty art. 237 .

"Id. art. 238 . 
on questions of principle, the contents of the agreement to associate can also be widely varied. It may range from institutional consultative machinery based on common objectives and, as in the case of the association agreement between the E.C.S.C. and the United Kingdom, containing nothing that, from the economic angle, conflicts with the most-favored-nation clause, to an agreement of very great economic substance such, for example, as a customs union.

Negotiations between the Community and Greece and between the Community and Turkey were begun under article $23^{8}$ of the Treaty. These negotiations have been conducted by the Common Market Commission. The two countries named were not invited to take part in the talks that led to the establishment of the E.F.T.A., since these were of a strictly commercial and industrial character that had little connection with the problems facing these two countries; both are in process of development, and any agreement necessarily implies an element of assistance to them. The E.E.C. felt that it was a political necessity to respond to their request.

At the time of writing, the negotiations with Turkey are still proceeding; but those with Greece culminated on March 30, I96I, in the signature of a draft agreement of association which is shortly to be concluded. The draft agreement is based on a customs union to be established between Greece and the Community over a transition period and intended to enable Greece to become, at a later date, when its economic progress allows, a full member of the Community. It also includes a number of protocols to take account of special aspects of the Greek economy, which had to be in a position to continue and even to accelerate its drive for modernization and industrialization. For this reason, it was necessary to include special measures such as the establishment of a longer transition period for certain products, or the protection by Greece of her new industries; the Community, for its part, will provide financial aid and will also take exceptional steps to improve Greek outlets in the Member Countries.

The draft agreement is not limited, moreover, to a mere customs union. Following the example of the Rome Treaty, and at the same time taking account of Greek needs and possibilities, it includes sections on the free movement of persons, services, and capital, transport, competition rules, and economic policy.

Most of these proposed measures refer expressly to the rules or principles of the Rome Treaty, but leave the details and conditions of their application to decision by the institutions set up under the Association Agreements.

It should also be pointed out that the association of the overseas territories as it was laid down in outline by the Treaty of Rome may be subject to certain amendments, if only because most of these countries have now become independent. This is one of the many points on which the particular responsibilities of the Community must be judged in the light of its wider role.

At the beginning of $\mathrm{r} 96 \mathrm{I}$, therefore, the E.E.C. found itself engaged in a series of negotiations stemming in part from its various responsibilities and in part from the clarification of its relationships with its main trading partners. 
The normal forum for these discussions is G.A.T.T. Talks are proceeding for the recognition of the common tariff, which, of course, is one of the essential elements of the customs union of the Six. It is certainly in conformity with the G.A.T.T. rules; nevertheless, its establishment implies a number of changes, and in particular the unbinding of duties, which must be studied by the nonmember countries under article XXIV (6) of the G.A.T.T. Convention. A difficulty, which is mainly one of timing, arises for agriculture: much of the common agricultural policy of the Six still remains to be worked out, whereas certain nonmember countries would like to obtain immediate and very precise guarantees on the effects of this policy on their trade.

As soon as the negotiations on the recognition of the Common Market's external tariff have ended, it will be possible to go on to the stage of tariff negotiations in the real sense of the word-that is, to reciprocal tariff concessions. In this field, the Community has proposed across-the-board reductions for the entire common tariff; these have already been mentioned in connection with the decision for the speedier implementation of the Treaty. In the Committee of Twenty-one, the Community has also proposed that, in view of the European problems, efforts should be coordinated in order to ensure that these negotiations produce the maximum effect.

Moreover, the Community shares in the other work of G.A.T.T.-that is to say, it is represented on the committees that deal more particularly with agricultural problems and with the relationship between countries in process of development and the industrialized countries. This does not exclude the search for solutions to any specific difficulties that may arise. Consultations have, for example, begun with certain Latin American countries.

Finally, on December 14, 1960, the O.E.E.C. was recast and a new body set up under the name of the Organization for Economic Cooperation and Development. This reorganization is largely in line with the principles that have guided the Community itself. The new Convention puts the United States, Canada, and all the European countries on an equal footing. Also, the traditional functions of the O.E.E.C. must now be considered in the light of the new situation in Europe and from the angle of the ever-growing importance of the relations not only between Europe and the rest of the world, but, more accurately, between the industrialized countries (be they European or American) and the countries in course of development.

It is against this background that the action of the industrialized countries should be coordinated, because it involves the most important of the responsible industrial countries, especially the United States, the Community, and the United Kingdom. The commercial problems of relations between the Six and the Seven could also be studied in this setting. Lastly, the more general coordination of western economic policies, and in particular of cyclical policies, should be examined in this framework.

Without encroaching upon the rights of G.A.T.T., which remains the organization with the widest membership, the importance of this intermediate group be- 
tween G.A.T.T. and the Europe of the Six is obvious, since it comprises both North America and the European countries. Permanent consultation and the preparation of decisions to be taken in the other organizations, either of a wider geographical compass such as G.A.T.T. or of a more specialized technical competence (monetary organizations, for example), could occur at this level.

\section{VI}

One finds, therefore, that by virtue of its novelty the establishment of the Common Market has given rise to apprehension in certain countries. But one must also remember that it has so far produced no real difficulties. Paradoxically enough, however, it is very much easier to tackle concrete difficulties and to find means of removing them than it is to allay fears. This leads one, I think, to the following concluding observations:

I The Common Market must not be judged from the commercial point of view alone, or without taking into account its contribution to European unification. But even from the economic point of view, the expansion that the Common Market is expected to bring should produce a favorable development of world trade from which all nonmember countries will benefit. In addition, the unification of the Six constitutes a new fact that will make it possible for these countries to play a greater positive part in attaining world equilibrium. Undeniably, the emergence of the Common Market has provoked a certain amount of rethinking in this field and has already brought forth proposals for reciprocal tariff reductions that are having a healthy influence on the trend of the world's economy.

2. This role of the Common Market as a driving force in both the economic and the political field is one of its essential features. The stronger the Community becomes and the more rapidly it is united, the more easily will it be able to play the positive role that can be rightly expected of it. This is the real significance of the fact that it was possible to couple the decision to accelerate the application of the Treaty with a decision at the same time to reduce the level of the common external tariff.

3. The Community remains open to any country wishing to join it or to associate itself with it. Clearly, this is the most complete sort of coordination the Common Market can offer; but it is not the only kind. A liberal policy practiced by the Common Market should also have excellent general results and should meet the problems of most nonmember countries.

The question of confidence in the future effects of the Common Market has been repeatedly brought up in the course of this paper. It is admittedly difficult to expect nonmember countries to accept more confidence in the internal expansion of the $\mathrm{Six}$ as an answer to their anxieties, just as it is difficult to ask the Community to doubt its own success, which would be contrary to its aims and contrary to the 
production and trade statistics already at its disposal. But it is here that one sees the full value of the liberal policy that the Community has proposed and begun to apply. This policy will further strengthen nonmember countries in their relations with the Common Market; and in the kind of gamble on the future represented by the unification of the Six, it will further reduce the measure of possible risk and increase the likelihood of a favorable outcome. Finally, moreover, this developing policy is a sign of the six countries' good will, a pledge that they are pursuing their unification not in the spirit of setting up a closed shop, but in that of making a new and fundamental contribution to the development of the free world. 